\title{
Choroidal neovascularization after blunt ocular trauma in angioid streaks
}

This article was published in the following Dove Press journal:

Clinical Ophthalmology

2 July 2013

Number of times this article has been viewed

\author{
Masaomi Kubota \\ Takaaki Hayashi \\ Kota Arai \\ Hiroshi Tsuneoka \\ Department of Ophthalmology, \\ The Jikei University School of \\ Medicine, Tokyo, Japan
}

Correspondence: Masaomi Kubota Department of Ophthalmology, The Jikei University School of Medicine, 3-25-8 Nishi-shimbashi, Minato-ku, Tokyo I05-846I, Japan

Tel +8I 33433 IIII (ext 358I)

Fax +81334331936

Email omiomi7725@jikei.ac.jp
Background: Patients with angioid streaks are prone to develop a subretinal hemorrhage after ocular injury, due to fragility of Bruch's membrane.

Objective: The purpose of this study was to report a patient with angioid streaks in whom subfoveal choroidal neovascularization (CNV) developed after blunt ocular trauma.

Case report: A 60-year-old man was accidentally struck in the left eye with a crowbar handle while engaged in the demolition of wooden building materials in May 2011 and was initially evaluated at our hospital. Corrected visual acuity was 0.3 in the right and 1.2 in the left eye, and relative afferent pupillary defect was negative. Funduscopy revealed choroidal atrophy around the optic papillae and angioid streaks radiating from around the optic discs in both eyes. In the right eye, there was macular atrophy. In the left eye, there was a subretinal hemorrhage around the macular region. Fluorescein angiography of the left eye showed a blockage due to subretinal hemorrhage and increasing hyperfluorescent spots superior to the fovea, suggestive of extrafoveal CNV. Spectral-domain optical coherence tomography showed macular thinning in the right eye and no obvious abnormalities near the subfoveal region in the left eye. Two months later, the patient noticed decreased visual acuity in the left eye and was reevaluated. Visual acuity had decreased to 0.7 , and well-defined CNV, one disc diameter in size, was presenting slightly superior to the macula, including the subfoveal region. Two weeks later, anti-vascular endothelial growth factor (anti-VEGF) antibody (bevacizumab) was injected intravitreally; the CNV then regressed, and visual acuity improved to 1.2 .

Conclusion: Marked improvement in visual acuity with early treatment has not been reported in angioid streaks with subfoveal CNV after ocular injury. Intravitreal injection of an anti-VEGF antibody should be considered early after the diagnosis of CNV.

Keywords: pseudoxanthoma elasticum, subretinal hemorrhage, anti-VEGF therapy

\section{Introduction}

Angioid streaks (AS) are characterized by linear irregularities radiating from around the optic disc due to a weakening or rupture of Bruch's membrane, elastic fiber degeneration, or calcium deposition at the same site. If these streaks reach the macular region, choroidal neovascularization (CNV) will occur under the macular region, resulting in severe visual impairment. CNV occurs in $72 \%-86 \%$ of cases of AS, ${ }^{1,2}$ and the Gass type II $\mathrm{CNV}$ seen in exudative age-related macular degeneration is common.

Significant visual impairment reportedly develops in $15 \%$ of patients with AS who suffer head trauma, ${ }^{3}$ and regular examination is required to assess changes before and after injury. As far as we have been able to determine, few reports have described the development of CNV after blunt trauma in AS patients. 
We report herein a case in which an AS patient who developed CNV after blunt trauma was treated with intravitreal injection of bevacizumab, an anti-vascular endothelial growth factor (anti-VEGF) antibody, soon after onset of CNV, resulting in improved visual acuity.

\section{Case report}

In May 2011, a 60-year-old man was accidentally hit in the left eye with a crowbar handle while engaged in the demolition of wooden building materials and underwent initial examination in our department on the same day. He was not wearing eye protection at the time of the trauma. His medical history included a fundal hemorrhage after having been hit in the right eye 3-4 years earlier. His family history was unremarkable. On initial examination, his best corrected visual acuity (BCVA) was 0.3 (with -1.50 diopters) in the right eye and 1.5 (with -3.00 diopters) in the left eye. The intraocular pressure was $15 \mathrm{mmHg}$ on the right and $22 \mathrm{mmHg}$ on the left. Light reflex was rapid in both eyes, and relative afferent pupillary defect was negative. Examination of the anterior segments showed a slight presence of inflammatory cells only in the left anterior chamber. Fundal examination revealed choroidal atrophy around the optic papillae and AS radiating from around the optic discs in both eyes. Atrophic changes to the macular region were evident in the right eye, and a subretinal hemorrhage was apparent around the macular region in the left eye (Figure 1A and B).

Two weeks later, fluorescein angiography (FA) (VISUCAM ${ }^{\mathrm{NMFA}}$; Carl Zeiss Meditec AG, Jena, Germany) was performed. The middle phase FA image of the right eye showed tissue staining and a window defect in the macular region (Figure 1C). The early phase FA image of the left eye revealed signs of blocking due to subretinal hemorrhage and hyperfluorescent spots due to early leakage superior to the fovea (Figure 1D). Additionally, the FA images of the middle (Figure 1E) and late (Figure 1F) phases showed increasing hyperfluorescence due to the leakage, suggestive of extrafoveal CNV. Spectral-domain optical coherence tomography (OCT) (Cirrus ${ }^{\mathrm{TM}}$ HD-OCT Model 4000; Carl Zeiss Meditec AG) using the HD 5-line raster scan protocol (horizontal scan of $6 \mathrm{~mm}$ ) revealed thinning of the central retina with subretinal tissue in the right eye (Figure 1G), but no obvious abnormality was seen in the neighborhood of the fovea in the left eye (Figure 1H). Examination of the skin revealed characteristic skin lesions on the neck (Figure 2A) and axillae on both the right (Figure 2B) and left side, suggestive of pseudoxanthoma elasticum.

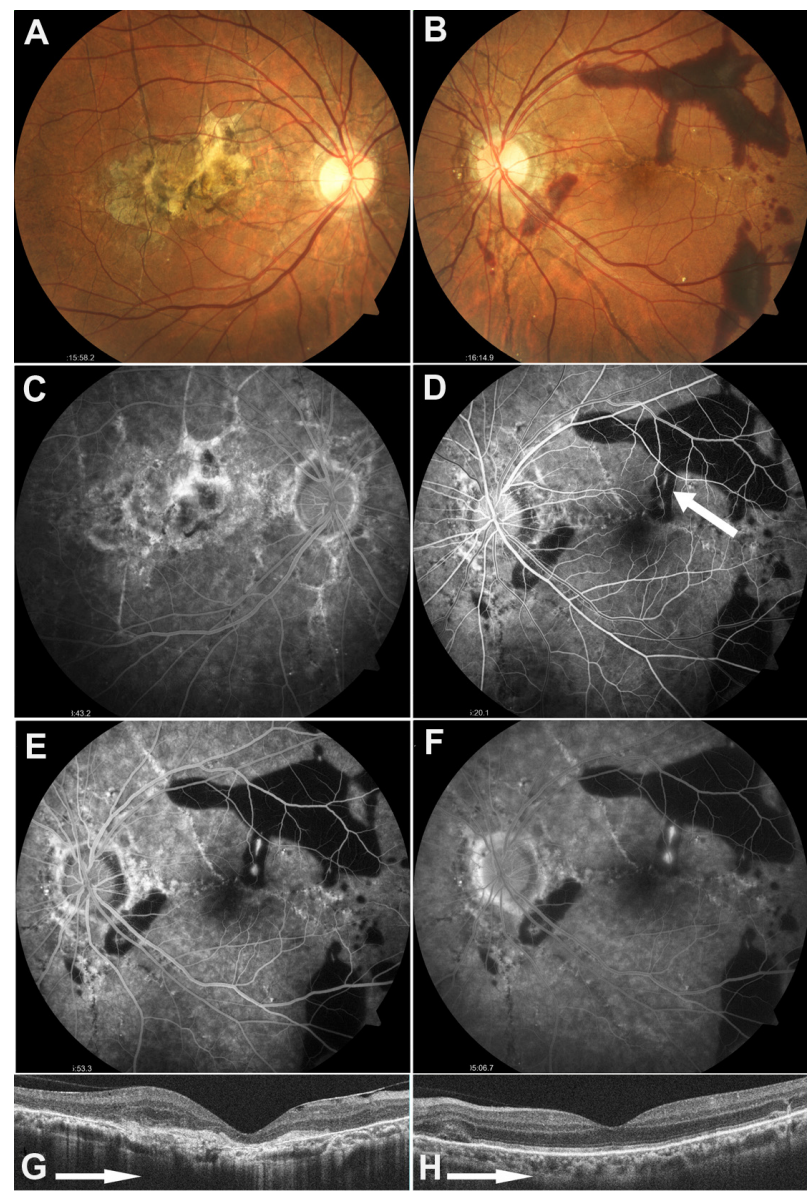

Figure I Fundus findings on initial examination.

Notes: (A and B) Fundus photographs: Choroidal atrophy around the optic papillae and angioid streaks radiating from around the optic discs are evident in both eyes. (A) Atrophic changes to the macular region are seen in the right eye, and (B) subretinal hemorrhage within the vascular arcade is apparent in the left; (C-F) Fluorescein angiograms 2 weeks after the onset: (C) Tissue staining and window defect are present in the macular region of the right eye. (D) The early phase image ( 25 seconds after injection) of the left eye reveals signs of blocking due to subretinal hemorrhage, and hyperfluorescent spots (arrow) due to early leakage superior to the fovea.The images of $(\mathbf{E})$ the middle phase ( 80 seconds after injection) and $(\mathbf{F})$ the late phase ( 10 minutes after injection) show increasing hyperfluorescence due to leakage, suggestive of extrafoveal choroidal neovascularization; ( $\mathbf{G}$ and $\mathbf{H}$ ) Optical coherence tomography: (G) Thinning of the macula is seen in the right eye, but $(\mathbf{H})$ the left eye shows no obvious abnormality in the neighborhood of the fovea.

The subretinal hemorrhage in the left eye was subsequently absorbed, but 2 months after the injury, the patient became aware of metamorphopsia in the left eye. One month later ( 3 months after the injury), BCVA in the patient's left eye had decreased to 0.7 , and welldefined CNV, one disc diameter in size, was evident somewhat above the macular region (Figure $3 \mathrm{~A}$ ). The extrafoveal CNV, which had developed superior to the fovea, progressed to a subfoveal location. OCT demonstrated that CNV was clearly located in the juxtafoveal (Figure 3B) and subfoveal (Figure $3 \mathrm{C}$ ) regions, extending across the retinal pigment epithelial line into the retina, resulting in Gass type 


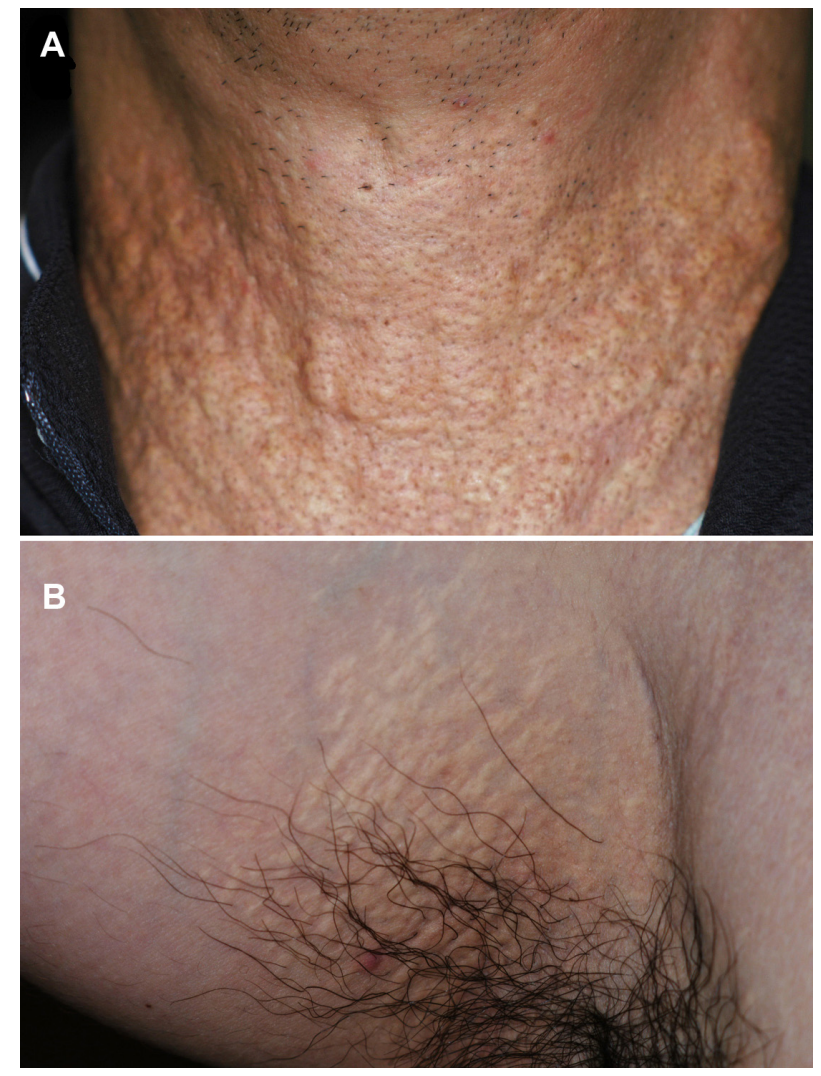

Figure 2 Appearance of the skin.

Note: Characteristic skin lesions on (A) the neck, and (B) the right axilla, suggestive of pseudoxanthoma elasticum.

II CNV. FA revealed well-defined, predominantly classic $\mathrm{CNV}$ in the early phase (Figure 3D) and a high level of fluorescein leakage coincident with $\mathrm{CNV}$ in the late phase (Figure 3E). CNV was also visualized on indocyanine green angiography (VISUCAM ${ }^{\mathrm{NM} / \mathrm{FA}}$ ) from the early phase (Figure 3F) to the late phase (Figure 3G).

Two weeks later (3.5 months after injury), as visual impairment persisted in the left eye, intravitreal injection of $1.25 \mathrm{mg} / 0.05 \mathrm{~mL}$ bevacizumab (Avastin ${ }^{\circledR}$; Genentech, South San Francisco, CA, USA) was administered. The offlabel use of bevacizumab was approved by the Institutional Review Board of The Jikei University. Visual acuity gradually improved and by approximately 2 months after starting intravitreal bevacizumab (IVB) had recovered to 1.2 in the left eye, with pronounced regression of the CNV (Figure 4A) and disappearance of the subfoveal CNV (Figure 4B). As of 1 year later, no further visual impairment has appeared.

\section{Discussion}

In the present patient, who had both AS and pseudoxanthoma elasticum, although visual acuity was excellent immediately

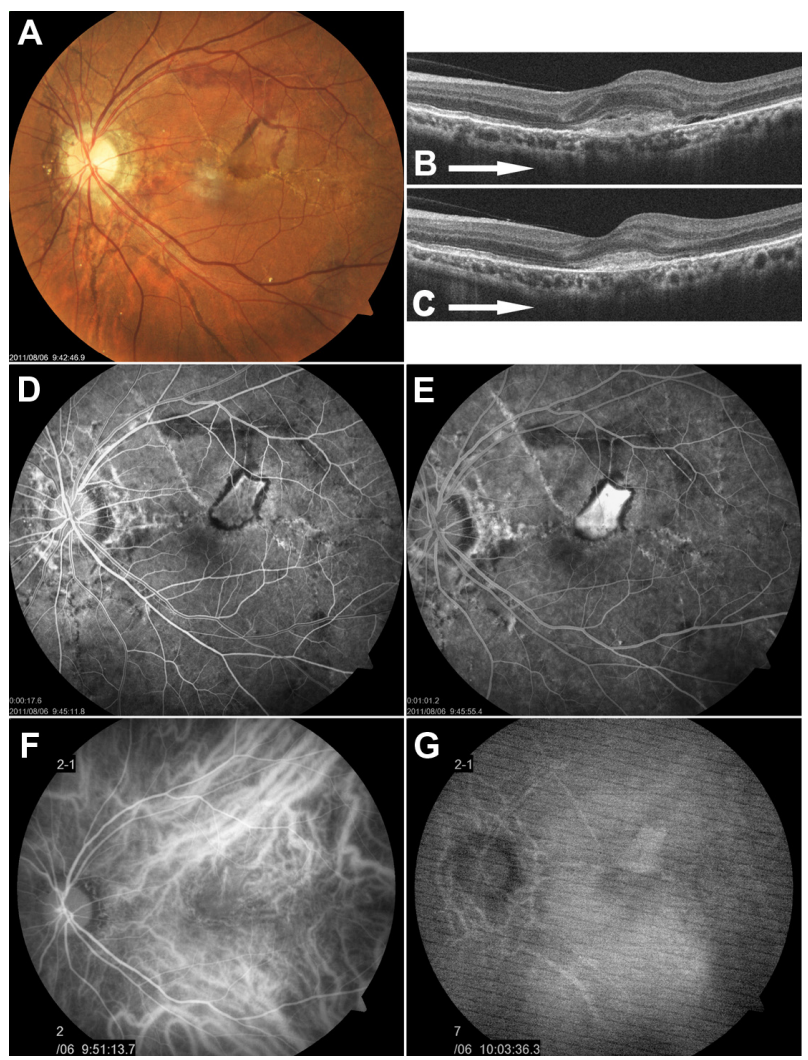

Figure 3 Left fundus findings 3 months after injury.

Notes: (A) Fundus photograph: Well-defined choroidal neovascularization (CNV), one disc diameter in size, is evident, somewhat above the macular region; ( $\mathbf{B}$ and $\mathbf{C}$ ) Optical coherence tomography: $\mathrm{CNV}$ is clearly located in the (B) juxtafoveal and (C) subfoveal regions, extending across the retinal pigment epithelium line into the retina, resulting in Gass type II CNV; (D and E) Fluorescein angiography: (D) Well-defined CNV is evident in the early phase (20 seconds after injection). (E) A high level of fluorescent leakage consistent with CNV is apparent in the late phase (10 minutes after injection); (F and $\mathbf{G}$ ) Indocyanine green angiography: CNV is visualized from $(\mathbf{F})$ the early phase (I minute after injection) to $(\mathbf{G})$ the late phase ( 13 minutes after injection).

after the blunt trauma, extrafoveal $\mathrm{CNV}$ appeared within 2 weeks after injury, and visual acuity decreased. No previous case reports have described improvements in visual acuity due to early administration of an anti-VEGF agent for $\mathrm{CNV}$ occurring after blunt injury in an AS patient. Pandolfo et $\mathrm{al}^{4}$ reported a case in which the use of laser photocoagulation was attempted to treat extrafoveal CNV that appeared 4 months after blunt trauma, but subfoveal CNV recurred, and a fibrous scar developed. Alpay and Caliskan ${ }^{5}$ reported that pronounced visual impairment, due to a fibrous lesion in the fovea, occurred 3 weeks after injury in an AS patient who had a macular subretinal hemorrhage and optic disc edema after blunt trauma, despite treatment with oral corticosteroids. De Benedetto et $\mathrm{al}^{6}{ }^{6}$ described an AS patient with a loss of visual acuity and extrafoveal CNV originating from choroidal rupture in the left eye, who had 


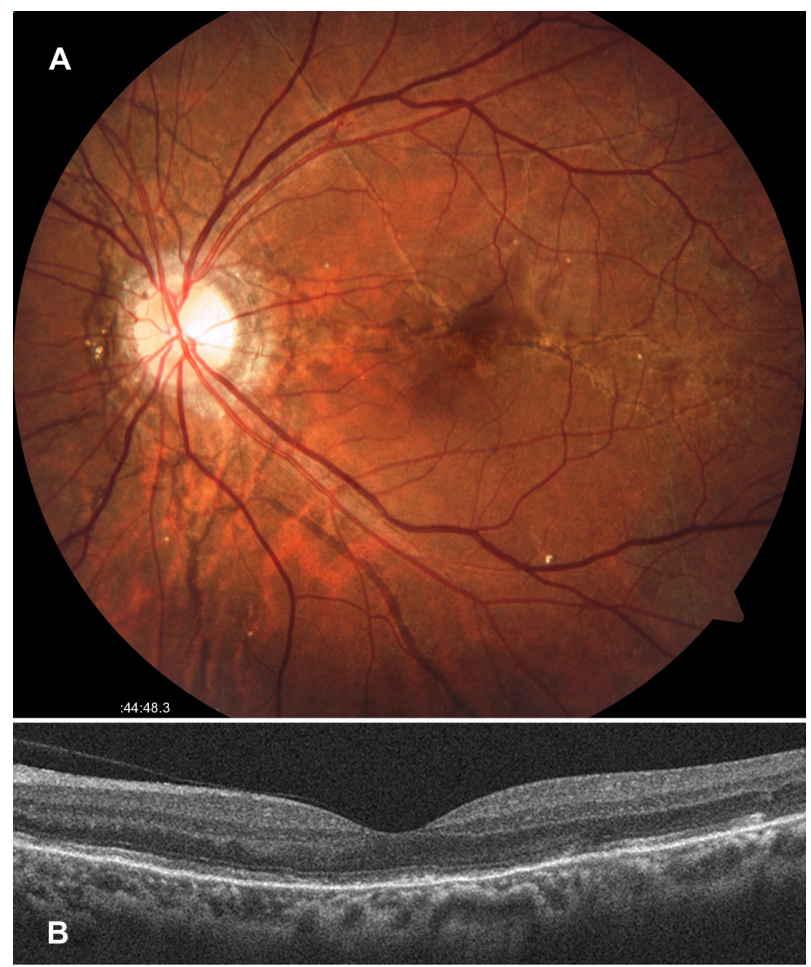

Figure 4 Left fundus findings 2 months after the intravitreal injection of bevacizumab.

Notes: (A) Fundus photograph reveals pronounced regression of choroidal neovascularization (CNV); (B) Optical coherence tomography by horizontal scan shows disappearance of subfoveal CNV.

suffered from ocular blunt trauma 1 year earlier, and reported that visual acuity in this patient remained unchanged after IVB injection. Although some reports have described the occurrence of subretinal hemorrhage following blunt trauma in AS patients, ${ }^{4,5,7,8}$ the subsequent incidence of $\mathrm{CNV}$ is not necessarily high.

Reported treatment for $\mathrm{CNV}$, as a complication of AS that is unrelated to ocular injury, include photodynamic therapy ${ }^{9-11}$ and intravitreal injection of the anti-VEGF antibodies bevacizumab ${ }^{12-16}$ and ranibizumab. ${ }^{17,18}$ Photodynamic therapy has a short-term effect and may help prevent visual impairment ${ }^{9,10}$ but has also been reported to cause enlargement of scarring and loss of vision over the long term. ${ }^{11}$ According to the majority of reports, ${ }^{12-18}$ bevacizumab and ranibizumab are effective in maintaining and improving vision over both the short and long terms, but often, repeated injections are needed. In the present case, we administered a single injection of IVB. CNV regressed after the injection, and marked improvements in visual acuity became evident, indicating that a single IVB injection was useful.

\section{Conclusion}

In the present case, a subretinal hemorrhage was evident immediately after injury, but extrafoveal CNV, which developed 2 weeks after injury, progressed to a subretinal location within 3 months after injury. It is important that construction workers who suffer from AS always wear goggles or other eye protection to protect their eyes while working because CNV may develop after blunt ocular trauma. When CNV develops, the administration of intravitreal anti-VEGF antibody as soon as possible should be considered.

\section{Acknowledgments}

This study was supported by grants from the Ministry of Health, Labor and Welfare of Japan (TH) and the Vehicle Racing Commemorative Foundation (TH and HT).

\section{Disclosure}

The authors report no conflicts of interest in this work.

\section{References}

1. Connor PJ Jr, Juergens JL, Perry HO, Hollenhorst RW, Edwards JE. Pseudoxanthoma elasticum and angioid streaks. A review of 106 cases. Am J Med. 1961;30:537-543.

2. Shields JA, Federman JL, Tomer TL, Annesley WH Jr. Angioid streaks. I. Ophthalmoscopic variations and diagnostic problems. Br J Ophthalmol. 1975;59(5):257-266

3. Georgalas I, Papaconstantinou D, Koutsandrea C, et al. Angioid streaks, clinical course, complications, and current therapeutic management. Ther Clin Risk Manag. 2009;5(1):81-89.

4. Pandolfo A, Verrastro G, Piccolino FC. Retinal hemorrhages following indirect ocular trauma in a patient with angioid streaks. Retina. 2002; 22(6):830-831

5. Alpay A, Caliskan S. Subretinal hemorrhage in a soccer player: a case report of angioid streaks. Clin J Sport Med. 2010;20(5):391-392.

6. De Benedetto U, Battaglia Parodi M, Knutsson KA, et al. Intravitreal bevacizumab for extrafoveal choroidal neovascularization after ocular trauma. J Ocul Pharmacol Ther. 2012;28(5):550-552.

7. Britten MJ. Unusual traumatic retinal haemorrhages associated with angioid streaks. Br J Ophthalmol. 1966;50(9):540-542.

8. Levin DB, Bell DK. Traumatic retinal hemorrhages with angioid streaks. Arch Ophthalmol. 1977;95(6):1072-1073.

9. Karacorlu M, Karacorlu S, Ozdemir H, Mat C. Photodynamic therapy with verteporfin for choroidal neovascularization in patients with angioid streaks. Am J Ophthalmol. 2002;134(3):360-366.

10. Menchini U, Virgili G, Introini U, et al. Outcome of choroidal neovascularization in angioid streaks after photodynamic therapy. Retina. 2004;24(5):763-771.

11. Heimann H, Gelisken F, Wachtlin J, et al. Photodynamic therapy with verteporfin for choroidal neovascularization associated with angioid streaks. Graefes Arch Clin Exp Ophthalmol. 2005;243(11):1115-1123.

12. Teixeira A, Moraes N, Farah ME, Bonomo PP. Choroidal neovascularization treated with intravitreal injection of bevacizumab (Avastin) in angioid streaks. Acta Ophthalmol Scand. 2006;84(6): 835-836.

13. Pedersen R, Soliman W, Lund-Andersen H, Larsen M. Treatment of choroidal neovascularization using intravitreal bevacizumab. Acta Ophthalmol Scand. 2007;85(5):526-533.

14. Rinaldi M, Dell'Omo R, Romano MR, Chiosi F, Cipollone U, Costagliola C. Intravitreal bevacizumab for choroidal neovascularization secondary to angioid streaks. Arch Ophthalmol. 2007;125(10): $1422-1423$.

15. Bhatnagar P, Freund KB, Spaide RF, et al. Intravitreal bevacizumab for the management of choroidal neovascularization in pseudoxanthoma elasticum. Retina. 2007;27(7):897-902. 
16. Wiegand TW, Rogers AH, McCabe F, Reichel E, Duker JS. Intravitreal bevacizumab (Avastin) treatment of choroidal neovascularisation in patients with angioid streaks. Br J Ophthalmol. 2009;93(1):47-51.

17. Finger RP, Charbel Issa P, Hendig D, Scholl HP, Holz FG. Monthly ranibizumab for choroidal neovascularizations secondary to angioid streaks in pseudoxanthoma elasticum: a one-year prospective study. Am J Ophthalmol. 2011;152(4):695-703.
18. Shah M, Amoaku WM. Intravitreal ranibizumab for the treatment of choroidal neovascularisation secondary to angioid streaks. Eye (Lond). 2012;26(9):1194-1198.

\section{Publish your work in this journal}

Clinical Ophthalmology is an international, peer-reviewed journal covering all subspecialties within ophthalmology. Key topics include: Optometry; Visual science; Pharmacology and drug therapy in eye diseases; Basic Sciences; Primary and Secondary eye care; Patien Safety and Quality of Care Improvements. This journal is indexed on

Submit your manuscript here: http://www.dovepress.com/clinical-ophthalmology-journal

\section{Dovepress}

PubMed Central and CAS, and is the official journal of The Society of Clinical Ophthalmology (SCO). The manuscript management system is completely online and includes a very quick and fair peer-review system, which is all easy to use. Visit http://www.dovepress.com/ testimonials.php to read real quotes from published authors. 